\title{
Hospital management training for the Eastern Mediterranean Region: time for a change?
}

\author{
Fauziah Rabbani, Farah Naz Hashmani, Aftab A. Ali Mukhi, \\ Xaher Gul, Nousheen Pradhan and Peter Hatcher \\ Department of Community Health Sciences, \\ Aga Khan University, Karachi, Pakistan \\ Mounir Farag \\ Health Systems and Services Development, Hospital Care and Management, \\ WHO Eastern Mediterranean Regional Office, Cairo, Egypt, and \\ Farhat Abbas \\ Section of Urology, Department of Surgery, \\ Aga Khan University, Karachi, Pakistan
}

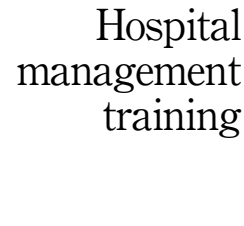

965

Received 27 November 2014 Revised 4 June 2015

29 June 2015

26 July 2015

Accepted 18 August 2015

\begin{abstract}
Purpose - The WHO Eastern Mediterranean Regional Office has emphasized health system strengthening among the top five strategic priorities. One of the integral elements of health systems are the hospitals. The purpose of this paper is to review the need for formalized training in hospital management to improve the quality of care.

Design/methodology/approach - Literature review and hands on experience of conducting a regional training in hospital management for Eastern Mediterranean Region (EMR) countries.

Findings - Majority of patients in EMR bypass Primary Health Care facilities due to inadequate quality of services and prefer seeking specialized care at a tertiary level. There is mounting evidence of mediocre to poor patient satisfaction due to inefficient health care practices in hospitals of EMR. Strengthening the management capacity of the hospitals through a formal training programme is therefore necessary for improving the performance of health care delivery and the overall health system. Hospital management encompasses hospital planning and operational activities including development and implementation of organizational strategies to ensure adequate numbers and quality of trained human resources and effective financial management, disaster management, health management information system utilization, support services, biomedical engineering, transport and waste management. Such training will prepare health care professionals with leadership skills to deliver quality hospital services.

Originality/value - This is one of the first papers emphasizing the need for a formal structured regional training in hospital management for the countries of EMR. A modular incremental training approach developing an EMR Credit Transfer and Accumulation system is proposed.
\end{abstract}

Keywords Hospital managers, WHO, Hospital management, EMR countries, Health systems, Formalized training

Paper type Viewpoint

(C) Rabbani, Hashmani, Mukhi, Gul, Pradhan, Hatcher, Farag and Abbas. Published by Emerald Group Publishing Limited. This article is published under the Creative Commons Attribution (CC BY 3.0) licence. Anyone may reproduce, distribute, translate and create derivative works of this article (for both commercial \& non-commercial purposes), subject to full attribution to the original publication and authors. The full terms of this licence may be seen at http://creativecommons.org/ licences/by/3.0/legalcode

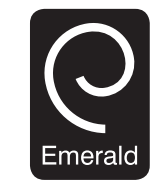

Journal of Health Organization and Management

Vol. 29 No. 7,2015 pp. $965-972$ Emerald Group Publishing Limited DOI 10.1108/JHOM-11-2014-0197 
JHOM

29,7

966

\section{Introduction}

Inequities in health, increasing health care costs, unacceptably low levels of access to quality health care and lack of a skilled health workforce represent some of the most important challenges facing many countries of the World Health Organisation Eastern Mediterranean Region (WHO EMR). In order to confront these challenges the WHO has emphasized health system strengthening among the top five strategic priorities for the next five years (WHO Regional Office for the Eastern Mediterranean (EMRO), 2007, 2009). Lack of expertise in management and weak leadership are the main reasons behind failure of many important health initiatives (Daire et al., 2014). Strong leadership and management capabilities have continued to be recognized as pivotal component for revitalizing health systems that are sensitive to population needs. This paper emphasizes the need for a formal structured regional training in hospital management for the countries of EMR. A modular incremental training approach developing an EMR Credit Transfer and Accumulation system is proposed.

\section{Managing under pressure: EMR and the hospital management crisis}

One of the most integral elements of health systems are hospitals which are resourceful, politically apparent, important and costly component of the health system (Harding and Preker, 2002). In the EMR (where 90 per cent are mostly low- and middle-income countries) a mixed type of health system comprising of several providers exists (Abdullatif, 2006). Hospitals both public and private remain one of the integral components of health systems of these countries. Keeping pace with latest medical and surgical technology, ensuring competent workforce and maintaining patient safety standards are some of the essential hospital functions which require a strong management and administrative capacity. The outcome of these management functions should aim at the well-being of patients through provision of the best possible quality of medical care, their safety and satisfaction, in a pleasant patient friendly hospital environment (Siddiqi et al., 2012). Ironically, in majority of these EMR countries patients bypass Primary Health Care facilities as a result of inadequate quality of services and prefer seeking specialized care at a tertiary level regardless of considerable additional time and financial costs (Rabbani, 2011).

The hospitals in the EMR countries are not well equipped to deal with this heavy and inappropriate influx of patients. The overall workforce density in this Region is below the global average of four skilled health workers per 1,000 population. Furthermore, eight countries of the EMR are classified as facing a crisis situation with regard to human resources for health. Much of this is due to: insufficient measures at entry, in particular lack of preparation of the workforce through strategic investment in education and effective and ethical recruitment practices (WHO EMRO, 2007, 2009). It is, therefore, not surprising that there is mounting evidence of mediocre to poor patient satisfaction due to inefficient health care delivery in hospitals of EMR (Razzak and Kellermann, 2002; Kianmehr et al., 2012; Pirkel et al., 2012; Amarapathy et al., 2003). There are also reports of up to 18 per cent of hospital patients in EMR suffering an adverse event while hospital acquired infections account for 5-10 per cent of hospitalized patients with up to 37 per cent being in the intensive care units (Asady, 2012). 


\section{Hospital management training: vital for health systems strengthening}

For effective health services delivery these EMR countries need to develop a motivated, well-managed and competent health workforce along with robust management strategies to ensure maximum output from minimum resources. Investment in management improves the health outcomes of the population (Mckinsey \& $\mathrm{Co}_{\text {., }}$ 2011) and can also contribute to attaining the health related Millennium Development Goals (Goals 4-6).

In many developing countries, the main reason for the failure of several public health measures is the paucity of managerial capacity (Rondinelli, 1976). This is understandable. There are no structured and specialized programmes of hospital management in these EMR countries. The specialized area of "Health and Hospital Management" is emerging and aligns well with the philosophy underpinning the WHO building blocks (especially Governance). By virtue of this, the public and private sector health services in EMR require well trained managers who can plan, implement and sustain the health programmes, services and structures in line with the needs of the population. This is even more crucial today as many countries in the EMR are experiencing dual burden of diseases (WHO EMRO, 2007) whereby both communicable and non-communicable chronic diseases put strain on the health system's resources and pose a significant challenge in terms of meeting the need for health care in the next few decades. Therefore the objective of providing quality and effective services with "maximum efficiency" now assumes the prime position on the health agenda of the countries today and for many years to come.

Hence, strengthening the management capacity within the health system (especially hospitals) is an important strategy for improving the performance of health care delivery and the overall health system. The rapid adoption of effective management practices and skills to supplement the clinical care and improve upon the patients' outcomes is a testament to the fact that "health care management" in recent years has evolved as an essential function and critical skill set in the domain of health services delivery.

Competent hospital managers are thus vital contributors to the effective performance of health systems. Besides being well versed with the management functions listed above they also have to play a leadership role to ensure proficient health service delivery and efficient resource utilization. Furthermore, these leaders (working in the EMR countries) need to direct hospital service delivery to address the major health problems faced by these countries including major disasters such as the earthquake in Pakistan (2005) and Islamic Republic of Iran (2003), drought in Somalia (2006) and landslides in Yemen (2005), to mention a few (El Morjani et al., 2007). Moreover the health systems of Pakistan, Afghanistan and Syria are further weakened by ongoing internal political conflicts and terrorism. An effective way to deal with these challenges requires training of human resources in hospital administration which will enable them to provide strategic direction in managing the particular situations faced by the hospitals in their respective countries. Elsewhere too, it has been documented that effective leadership in hospital management influences the social milieu, improves the quality of health care delivery and ensures patient safety (Buttigieg and West, 2013).

At national level, leadership usually includes making strategic decisions and working towards formulating policies, setting direction and targets for populations served by the hospitals. Facility managers at the operational level are however required for effectively managing day-to-day hospital functions
Hospital
management
training

967 
JHOM 29,7

968 operationalizing inputs and resources to meet the demands of patients (World Health Organization, 2009). It is usually observed that health managers in developing countries are health professionals or clinical experts who lack any prior training or experience in management and leadership but are responsible for managing large hospitals (Dorros, 2006). These health professionals are then expected to gain managerial exposure by either on-the-job training or through participating in short courses and workshops (Egger et al., 2005). Such on-the-job training can adopt action learning approaches to enhance the required managerial skills. It is noteworthy that many international global health organizations such as Global Alliance for Vaccine and Immunizations, Global Fund to Fight Aids, Tuberculosis, and Malaria organize various training courses and workshops for managers working in their disease specific health programmes. Around 120 management tools are developed by the WHO alone in the area of leadership and management (Egger et al., 2005).

\section{Management problems with management solutions}

Hospital management is however a specialized discipline demanding appropriate training and skills and cannot be solely acquired on job. It encompasses hospital planning and operational activities including development and implementation of organizational strategies to ensure adequate numbers and quality of trained human resources, effective financial management, disaster preparedness, health management information system utilization, support services, biomedical engineering, transport and waste management to mention a few (Sharma and Zodpey, 2011).

Literature supports that in order to retain and motivate health workforce they should be incentivized. Besides on-the-job training, post graduate training and opportunities for improving qualification through formal means are equally important (Nartker et al., 2010).

Regardless of improvement in modernizing medical and nursing curricula in some institutions of the EMR, the majority of schools still pursue traditional programmes which generally, have not progressed to become "competency-based". Explicitly medical and nursing undergraduate curriculum in the EMR does not impart appropriate skills in hospital management (WHO EMRO, 2007). A quick desk review done for the purpose of this paper reveals that majority of the universities and institutions in EMR are only offering short courses and certificate programmes in hospital management. In Pakistan, specifically hospital management is nested within more broad-based master level degrees like health administration, pharmaceutical management and business administration, etc. Very few institutions in Pakistan offer a specialized diploma in hospital management. A proper post graduate degree in hospital management imparting the required theoretical and practical competencies is therefore urgently needed.

Challenges such as demanding work schedule, personal and professional responsibilities and long absence from home and work can all denote major barriers for those keen to improve their professional skills via formal degrees. For such working professionals many institutions these days offer certified distance learning courses which reduces the pressure of time constraints. Additionally, this approach could also be used as an effective strategy to retain health management professionals working in EMR countries rather than encouraging pursuit of degrees in the west with resulting brain drain (Awases et al., 2004). 
After going through the management training which basically provides the technical skills, several experienced and trained managers who develop leadership qualities such as ability to think strategically, influence and motivate people and take timely decisions must be promoted or incentivized. The latter can be done by providing an opportunity to take advanced leadership training. This can lead to a positive change, particularly in challenging environments of the EMR countries. Effective senior leadership in hospitals influences the social milieu, promotes delivery of quality health care services, ensuring patient safety and positive professional development (Buttigieg and West, 2013).

Experiences of countries having successful formal training programmes in the area of hospital management and leadership must be evaluated so that lessons learnt can be translated to other similar country settings.

\section{The next step forward: proposed training approach in EMR}

In the EMR, there are no such programmes that have been designed with a clear focus and insight of the health needs of these countries. Therefore, to improve hospital performance in the EMR, it is proposed that a high-caliber university from the region serves as a nexus to offer a modular incremental training approach developing an EMR Credit Transfer and Accumulation system (EMR-CTS) for the acquisition of a higher degree. This could be developed on the lines of the European Credit Transfer and Accumulation System (ECTS). The latter is a standard for comparing the study attainment and performance of students of higher education across the European Union and other collaborating European countries. For successfully completed studies, ECTS-credits are awarded. One academic year corresponds to 60 ECTS-credits that are equivalent to 1,500-1,800 hours of study. This system facilitates transfer and progression to a higher degree throughout the Union. The same method can be used across EMRO region for providing in country face-to-face and online training options, facilitating incremental skill development for hospital managers at various levels (Figure 1). This EMR-CTS system will be credible in itself and also an avenue for accumulation of credits towards an ultimate formal graduate level degree (masters, $\mathrm{PhD}$ ) in the respective EMR countries.

\section{Conclusion}

The purpose of this paper is to highlight that with changing health care landscapes the need for imparting structured professional training for hospital managers working in EMR is imminent.

Thus hospital management must now be recognized as a specialized field. Adequate availability of the funds is necessary for continuing professional education and formal training in hospital management. It is imperative that, health departments should incentivize hospital managers by defining a career ladder which includes structured training and academic recognition of hospital management competencies for professional advancement. The health ministries of the countries of the EMR should develop a nationwide, need-based curriculum for formal training in hospital management. Universities including academic departments, schools of public health and graduate professional education institutes within EMR must all integrate to play a key role and consider offering more accessible and customized formal courses for hospital managers. 
JHOM

29,7

970

Figure 1.

Proposed themes and roadmap for formal training in hospital management for the countries of EMR

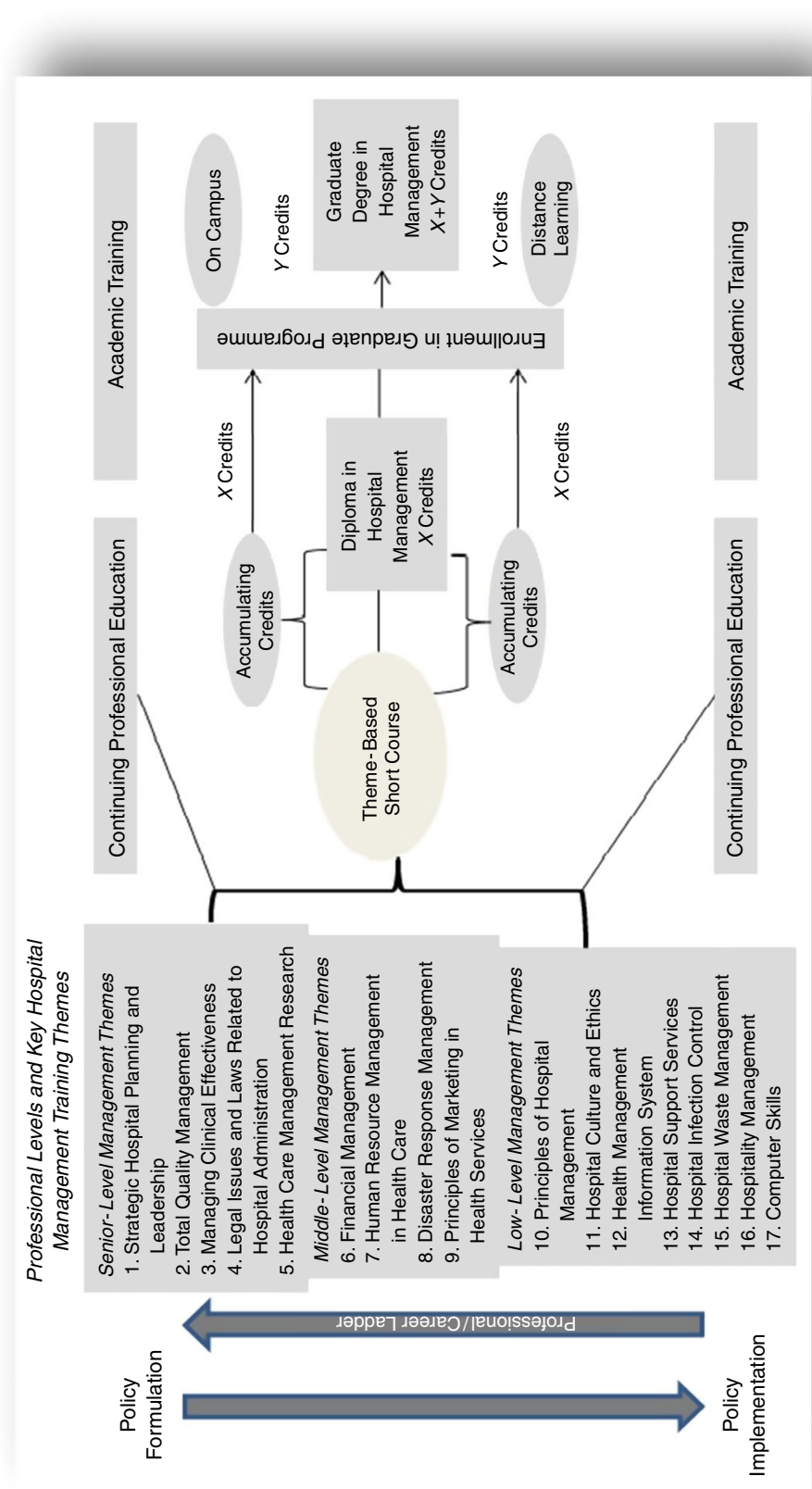




\section{Acknowledgements}

Conflict of interest: the authors declare that there is no conflict of interest.

The authors would like to thank WHO Eastern Mediterranean Regional Office, Division of Health Systems and Services Development, Hospital Care and Management, for their continued support and assistance. At Department of Community Health Sciences (CHS), Aga Khan University Karachi, the co-authors have formed a team to deliver short-capacity building courses on hospital management at regional and international level. Besides the authors listed, Drs Shagufta Perveen, Saleem Iqbal and Colonel Rashid Iqbal Khan, Nadira Ashraf and Amin Hirani contribute to these courses from CHS. In 2014 CHS offered a course on Hospital Management for countries of the EMR in which 20 participants from seven EMR countries came to Karachi (www.emro.who.int/information-resources/vhslinstitutional-digital-repository/meeting-reports.html).

\section{References}

Abdullatif, A.A. (2006), "Hospital care in WHO Eastern Mediterranean Region: an agenda for change", International Hospital Federation Reference Book, 2005/2006, World Health Organization, Geneva, p. 14.

Amarapathy, S., Sridharan, S., Perera, R., and Handa, Y. (2003), "Factors affecting patient safety culture in a tertiary care hospital in Sri Lanka", International Journal of Scientific \& Technology Research, Vol. 2 No. 3.

Asady, R. (2012), "Patient safety standards in developing countries of the WHO/Eastern Mediterranean region", WHO/EMRO ISQua-29th International Conference CICG, Geneva, 20-24 October.

Awases, M., Gbary, A., Nyoni, J. and Chatora, R. (2004), Migration of Health Professionals in Six Countries: A Synthesis Report, WHO Regional Office for Africa, Brazzaville.

Buttigieg, S.C. and West, M.A. (2013), "Senior management leadership, social support, job design and stressor-to-strain relationships in hospital practice", Journal of Health Organization and Management, Vol. 27 No. 2, pp. 171-192.

Daire, J., Gilson, L. and Cleary, S. (2014), "Developing leadership and management competencies in low and middle-income country health systems: a review of the literature". Working Paper No. 4, UKaid.

Dorros, G.L. (2006), Building Management Capacity to Rapidly Scale Up Health Services and Outcomes, World Health Organization, Geneva.

Egger, D., Travis, P., Dovlo, D. and Hawken, L. (2005), "Strengthening management in low-income countries", Working Paper No. 1, Department of Health System Policies and Operations Evidence and Information for Policy, WHO, Geneva.

El Morjani, Z.E.A., Ebener, S., Boos, J., Abdel Ghaffar, E. and Musani, A. (2007), "Modelling the spatial distribution of five hazards in the context of the WHO/EMRO Atlas of disaster risk as a step towards the reduction of the health impact related to disasters", International Journal of Health Geographics, Vol. 6 No. 8 p. 1-28

European Credit Transfer and Accumulation System. "European Commission, Education and Training", available at: http://ec.europa.eu/education/tools/ects_en.htm (accessed 23 October 2014).

Harding, A. and Preker, A.S. (2002), A Conceptual Framework for Organizational Reforms in the Hospital Sector, Innovations in Health Service Delivery: Volume I- The Corporatization of Public Hospitals, World Bank, Washington, DC. 
JHOM

29,7

Kianmehr, N., Mofidi, M., Saidi, M.H., HajiBeigi, M. and Rezai, M. (2012), "What are patients' concerns about medical errors in an emergency department?", Sultan Qaboos University Medical Journal, Vol. 12 No. 1, pp. 86-92.

Mckinsey \& Co. (2011), Management Matters in Health Care: Why Good Practice Really Matters, McKinsey \& Co. and The Centre for Economic Performance.

Nartker, A.J., Stevens, L., Shumays, A., Kalowela, M., Kisimbo, D. and Potter, K. (2010), "Increasing health worker capacity through distance learning: a comprehensive review of programmes in Tanzania”, Human Resources for Health, Vol. 8 No. 30, pp. 1-10.

Pirkel, C.M., Dumont, A. and Zunzunegui, M.V. (2012), "Medical record keeping, essential but overlooked aspect of quality of care in resource-limited settings", International Journal for Quality in Health Care, Vol. 24 No. 6, pp. 564-567.

Rabbani, F. (2011), "lmproving quality of care in hospitals: is there a role for performance management?", Pakistan Journal of Public Health, Vol. 1 No. 1, pp. 53-55.

Razzak, J.A. and Kellermann, A.L. (2002), "Emergency medical care in developing countries: is it worthwhile", Bulletin of the World Health Organization, Vol. 80 No. 10, pp. 900-905.

Rondinelli, D.A. (1976), "Why development projects fail: problems of project management in developing countries", Project Management Quarterly, Vol. 7 No. 1, pp. 10-15.

Sharma, K. and Zodpey, S. (2011), "Health and hospital management education in India", Health Line, Vol. 2 No. 1, pp. 13-16.

Siddiqi, S., Elasady, R., Khorshid, I., Fortune, T., Leotsakos, A., Letaief, M., Qsoos, S., Aman, R., Mandhari, A., Sahel, A., El-Tehewy, M. and Abdellatif, A. (2012), "Patient safety friendly hospital initiative: from evidence to action in seven developing country hospitals", International Journal for Quality in Health Care, Vol. 24 No. 2, pp. 144-151.

WHO Regional Office for the Eastern Mediterranean (EMRO) (2007), "Health systems strengthening in countries of the Eastern Mediterranean Region: challenges, priorities and options for future action”, Document EM/RC59/Tech.Disc. No. 1, technical paper presented to the Fifty-Ninth Session of the WHO Regional Committee for the Eastern Mediterranean, Cairo.

WHO Regional Office for the Eastern Mediterranean (EMRO) (2009), "Improving hospital performance in the Eastern Mediterranean Region", Document No. EM/RC56/RC, Resolution presented to the Fifty-sixth Session of the WHO Regional Committee for the Eastern Mediterranean, Cairo.

World Health Organization (2009), "Who are health managers: case studies from three African countries", Human Resources for Health Observer, Vol. 1, World Health Organization, Geneva, pp. 1-13.

\section{Corresponding author}

Professor Fauziah Rabbani can be contacted at: fauziah.rabbani@aku.edu

For instructions on how to order reprints of this article, please visit our website:

www.emeraldgrouppublishing.com/licensing/reprints.htm

Or contact us for further details: permissions@emeraldinsight.com 